\title{
Neurogenic stuttering and lateralized motor deficits induced by tranylcypromine
}

\author{
J. D. Duffy \\ Department of Psychiatry, Medical College of Pennsylvannia and Hahnemann University \\ Medical School, and Allegheny Neuropsychiatric Institute, Department of Psychiatry, 7777 \\ Steubenville Pike, Oakdale, PA 15071, USA
}

\begin{abstract}
A case of neurogenic stuttering induced by the monoamine oxidase inhibitor tranylcypromine is described. The association of neurogenic stuttering with acquired lateralized motor deficits in the patient described is discussed with reference to current theories regarding the pathogenesis of neurogenic stuttering.
\end{abstract}

Keywords: Dominance - Stuttering - Tranylcypromine

\section{INTRODUCTION}

Although there is currently no universally accepted definition of primary developmental stuttering, Wingate's description appears to be the most accurate and succinct definition of the disorder, i.e. "Stuttering is a disruption in the fluency of verbal expression characterized by involuntary audible or silent repetitions or prolongations in the utterance of short speech elements, e.g. sounds, syllables, and words of one syllable" (Wingate, 1964). Neurogenic stuttering (also referred to as "acquired stuttering") has also not been clearly defined but it may probably be most accurately, and simply, described as a "stutter-like" speech disruption secondary to nervous system damage (Canter, 1971). Neurogenic stuttering has been associated with a number of neurological conditions including cerebrovascular accidents, head trauma, Parkinson's disease and haemodialysis dementia (Rosenbek et al., 1975, 1978; Soroker et al., 1990). In addition, neurogenic stuttering has been reported to have been induced by psychotropic agents including phenothiazines (Nurnberg and Greenwald, 1981), alprazolam (Elliott and Thomas, 1985), tricyclic antidepressants (Quaker, 1977) and theophylline (McCarthy, 1981). Most of the case reports of verbal dysfluency occurring in association with antidepressant medications describe speech blockage and word finding difficulties, rather than phonation difficulty (i.e. stuttering), as the predominant characteristic of the patient's verbal dysfluency (Brady, 1991). Helm et al. (1978) identified five characteristics that apparently differentiate acquired stuttering from primary developmental stuttering. These are: (1) no adaption effect (i.e. the subject does not exhibit increasing fluency with practice); (2) repetitions, prolongations, and blocks not restricted to initial syllables; (3) stuttering on small grammatical words as well as substantive words; (4) possible annoyance but not anxiety; (5) rare secondary symptomatology such as facial grimacing and fist clenching.

This report describes a case of neurogenic stuttering induced by the monoamine oxidase inhibitor tranylcypromine. It is interesting to note that although a review of the literature reveals one previous report of neurogenic stuttering by phenelzine (another monoamine oxidase inhibitor), another recent case report describes a patient whose verbal dysfluency actually improved on tranylcypromine (Goldstein and Goldberg, 1986; Oberlander, 1993).

The occurrence of neurogenic stuttering with concurrent lateralized motor deficits in this case report is a provocative clinical finding that is discussed in the light of current theories regarding the pathogenesis of stuttering. This clinical association is particularly interesting in the context of current theories of stuttering that propose a dysregulation of the left hemisphere's usual dominance for fluent speech production.

\section{CASE REPORT}

The patient, a 14 year old left-handed female, was admitted to the adolescent psychiatric unit following repeated runaways, suicidal ideation and conflict with her parents. Upon admission, she met DSM-III-R 
TABLE I. Patient's speech productivity and lateralizing hand motor function on and off tranylcypromine

\begin{tabular}{|c|c|c|c|c|}
\hline Measure & $\begin{array}{c}\text { On } \\
\text { tranylcypromine }\end{array}$ & $\begin{array}{l}\text { Two days post- } \\
\text { tranylcypromine }\end{array}$ & $\begin{array}{l}\text { Eleven days post- } \\
\text { tranylcypromine }\end{array}$ & Comments \\
\hline Grooved pegboard test & $\begin{array}{l}L, 75 \mathrm{~s} \\
\mathrm{R}, 71 \mathrm{~s}\end{array}$ & $\begin{array}{l}\mathrm{L}, 61 \mathrm{~s} \\
\mathrm{R}, 60 \mathrm{~s}\end{array}$ & $\begin{array}{l}L, 65 \mathrm{~s} \\
\mathrm{R}, 68 \mathrm{~s}\end{array}$ & $\begin{array}{l}\text { Measures the time } \\
\text { required to } \\
\text { complete pegboard } \\
\text { (normal range: dominant } \\
\text { hand } 62.6-77.6 \mathrm{~s} \text {, non- } \\
\text { dominant } 53.2-79.8 \mathrm{~s} \text { ) }\end{array}$ \\
\hline Finger oscillation test & $\begin{array}{l}L, 31.4 \\
R, 33.8\end{array}$ & $\begin{array}{l}\mathrm{L}, 40.6 \\
\mathrm{R}, 31.4\end{array}$ & $\begin{array}{l}\mathrm{L}, 41.0 \\
\mathrm{R}, 37.2\end{array}$ & $\begin{array}{l}\text { Measures average } \\
\text { number } \\
\text { of taps in } 10 \mathrm{~s} \\
\text { (normal range: dominant } \\
\text { hand } 40.8-49, \text { non- } \\
\text { dominant } 35.5-44.5 \text { ) }\end{array}$ \\
\hline Verbal fluency & 14 & 29 & 32 & $\begin{array}{l}\text { F-A-S words } \\
\text { (normal 37.3-5.3 words } \\
\text { in } 2 \text { min). }\end{array}$ \\
\hline Non-verbal agility & 12 & 26.5 & 29 & $\begin{array}{l}\text { From the Boston } \\
\text { Diagnostic Aphasia } \\
\text { Examination (16). } \\
\text { Qualitative }\end{array}$ \\
\hline Verbal agility & 8 & 25 & 43 & $\begin{array}{l}\text { From the Boston } \\
\text { Diagnostic Aphasia } \\
\text { Examination. Qualitative } \\
\text { (16) }\end{array}$ \\
\hline
\end{tabular}

criteria for a severe major depressive disorder with suicidal ideation and melancholia. As the patient was adopted, no formal biological family history was available. The patient and her family were unaware of any traumatic birth injury or delayed developmental milestones. There was no significant previous medical history. She had no identified allergies.

Upon admission, physical examination revealed a left-handed female with normal physical and sexual development. Neurological examination was normal with no focal neurological deficits identified. Prior to receiving tranylcypromine she exhibited no unusual facial movements and made good eye contact.

Psychological evaluation demonstrated a severe level of depression, an external locus of control and features consistent with a borderline personality disorder. The patient produced a verbal IQ of 113, performance IQ of 106 and full score IQ of 111 on the WAIS-R.

The patient was started on desipramine and maintained on a dose of $200 \mathrm{mg}$ orally for approximately 2 months. Despite this, her affective disorder failed to improve and following an appropriate "washout" interval of 2 weeks and tyramine-free diet she was placed on tranylcypromine starting at $10 \mathrm{mg}$ p.o. twice daily. Three days following the introduction of the monoamine oxidase inhibitor the patient was noted to have developed mild stuttering. Following an increase of the tranylcypromine to $30 \mathrm{mg}$ daily, there was a further increase in the patient's verbal dysfluency.

Assessment of the patient's speech pattern demonstrated a severe dysfluency characterized by audible repetitions, prolongations, hesitations and blocks of initial phonemes. Dysfluent behaviors were noted on 304 of a 900 word, 10 minute speech sample. Secondary speech characteristics included poor eye contact, circumlocutions and laryngeal and labial tensions. The verbal dysfluencies persisted with singing and miming. These speech characteristics were therefore characteristic for stuttering rather than word finding difficulties.

Neuropsychological testing at this time revealed reduced verbal and non-verbal agility as measured by components of the Boston Diagnostic Aphasia examination (Goodglass and Kaplan, 1983). The patient exhibited decreased performance in her left dominant hand on the grooved pegboard and finger oscillation tests (Table I). Auditory verbal learning and written fluency were measured to be within normal limits. In view of the patient's increasing dysfluency, tranylcypromine was discontinued 11 days after starting it. The neuropsychological battery described above was repeated on Days 2 and 11 after discontinuing the drug. This serial testing demonstrated that the patient's improving verbal fluency directly correlated with an improvement in her left-sided motor skills. 
Electroencephalography performed several weeks after discontinuation of tranylcypromine demonstrated a minor background dysrhythmia bilaterally which consisted of scattered sharp forms, no paroxysmal abnormalities and an alpha background frequency of $12 \mathrm{~Hz}$.

In the 6 month period following the discontinuation of tranylcypromine the patient has exhibited no further stuttering.

\section{DISCUSSION}

A number of theories have been proposed to describe the pathogenesis of neurogenic and developmental stuttering. The production of normal fluent speech is a complex function involving both cerebral hemispheres. In the left hemisphere-dominant individual, the left hemisphere with its greater neural mass in the left planum temporale area and its specific left thalamic functions appears to be specialized for timedependent, non-segmental (i.e. semantic) speech functions (Moore, 1984).

Early speech theorists postulated that primary developmental stuttering occurs as a consequence of inadequate dominance by the "appropriate" dominant (usually left) hemisphere with a resultant desynchronization of speech production (Orton, 1927). More recent research utilizing regional cerebral blood flow studies (Stump and Williams, 1980; Denays et al., 1989; Pool et al., 1991), electroencephalographic mapping (Boberg et al., 1983) and tachistoscopic visual procedures (Moore, 1976) have suggested left frontal and peri-sylvian dysfunction in patients who stutter. Poole et al. (1991), utilizing ${ }^{133} \mathrm{Xe}$ single photon emission computed tomography, demonstrated significant relative flow asymmetries (left $<$ right) in the anterior cingulate superior and middle temporal gyri. This lateralized dysfunction is postulated to produce a reversed cerebral dominance with right hemispheric semantic functioning assuming a dominance for speech among stutterers. In the light of these findings, neurogenic stuttering may be postulated to occur as a result of an acquired dysregulation of the left hemisphere's usual dominant role in the production of fluent speech. This hypothesis is not supported however by a review of 10 patients who developed chronic acquired stuttering after sustaining penetrating brain lesions. This study reported that the penetrating lesions associated with acquired stuttering most frequently involved the internal and external capsules, frontal white matter and striatum with a uniform bilateral distribution (Ludlow et al., 1987). In the light of current conflicting clinical evidence the pathophysiology of stuttering therefore remains unclear.
The fact that the patient described in this paper normally exhibited left hand motor dominance raises doubts about her hemispheric specialization for "phonologic" and "semantic" speech production. In view of the theories described above it is possible that she possessed reversed dominance for speech production. The mechanism by which tranylcypromine produced apparent right hemisphere motor dysfunction and verbal dysfluency in the patient described is uncertain. It is interesting to note that the patient had previously received desipramine at therapeutic oral dosages without any adverse effect upon her speech production. This would suggest that, as has been postulated previously (Schatzberg et al., 1978), the anticholinergic activity of tranylcypromine is probably not implicated in the pathogenesis of this patient's stuttering.

Haloperidol has demonstrated efficacy in improving the verbal fluency of "developmental" stutterers. Wood et al. (1980) have demonstrated shifts in regional cerebral blood flow from the non-dominant (i.e. right) to the dominant (i.e. left) hemisphere in patients whose dysfluency improved on haldol. It is possible therefore that the dopaminergic activity of tranylcypromine may be implicated in this described patient's shift in motor dominance and concomitant dysfluency. The apparent laterality of tranylcypromine's action upon this patient's right hemisphere is intriguing. Whether this represents an idiosyncratic neurodevelopmental vulnerability in this patient or relative specificity of tranylcypromine's activity to the right hemisphere is open to speculation. It is interesting to note a single case study which demonstrated a differential effect of lithium upon the right hemisphere as measured by dichotic listening indices (Haran et al., 1987). Although there is literature to support the concept of a differential involvement of right and left hemisphere structures in primary and secondary mood disorders (Flor-Henry, 1983; Robinson and Starkstein, 1990), and the biogenic amines serotonin and dopamine have been shown to exhibit modest lateralization to the right and left hemisphere, respectively (Glick, 1983; Arato et al., 1991), there has been very little work attempting to identify any lateralizing specificity in the effect of psychotropics. Further research in this area offers the opportunity for a better understanding of psychotropic drug action and the genesis of behavioral disorders.

\section{REFERENCES}

Arato M, Frecska E, Tekes K and MacCrimmon DJ (1991) Serotinergic interhemispheric asymmetry: gender difference in the orbital cortex. Acta Psychiatrica Scandinavica, 84, 110-111. 
Boberg E, Yendall L, Schopflocher D and Bolarsen (1983) The effects of an intensive behavioral program on the distribution of EEG alpha power in the processing of verbal and visuospatial information. Journal of Fluency Disorders, 8, 245-263.

Brady JP (1991) The pharmacology of stuttering: a critical review. American Journal of Psychiatry, 148, 13091316.

Canter GJ (1971) Observations in neurogenic stuttering; a contribution to differential diagnosis. British Journal of Disorders of Communication, 6, 139-143.

Elliot RL and Thomas BJ (1985) A case report of alprazolam induced stuttering. Journal of Clinical Psychopharmacology, 5, 159-160.

Flor-Henry P (1983) Cerebral Basis of Psychopathology. Wright, Boston

Glick SD (1982) Lateral asymmetry of neurotransmitters in human brain. Brain Research, 234, 53-63.

Goldstein DM and Goldberg RL (1986) Monoamine oxidase inhibitor-induced speech blockage. Journal of Clinical Psychiatry, 47, 604.

Goodglass H and Kaplan E (1983) The Assessment of Aphasia and Related Disorders, 2nd edn. Lea \& Febiger, Philadelphia.

Haran G, Karnay N and Nachson I (1987) Effects of lithium carbonate on lateralised cognitive functions. Journal of Nervous and Mental Diseases, 175, 688-691.

Helm NA, Butler RB and Benson DF (1978) Acquired stuttering. Neurology, 28, 1159-1165.

Ludlow CL, Rosenberg J, Salazar A, Grafman J and Smutok M (1987) Site of penetrating brain lesions causing acquired stuttering. Annals of Neurology, 22, 6066.

McCarthy MM (1981) Speech effect of theophylline. Pediatrics, 68, 750-751.

Moore SHE (1976) Bilateral tachistoscopic word perception of stutterers and normal subjects. Brain and Language, 3, 434-442.

Moore SHE (1984) Central nervous system characteristics of stutterers. In: The Nature and Treatment of Stuttering (Eds RF Currie and WH Perkins). College Hill Press Inc.

Nurnberg HG and Greenwald B (1981) Stuttering: an unusual side effect of phenothiazines. American Journal of Psychiatry, 138, 386-387.

Oberlander F, Schneier F, Liebowitz MR (1993) Treatment of stuttering with phenelzine. American Journal of Psychiatry, 150, 355.

Orton ST (1927) Studies in stuttering. Archives of Neurology, 18, 671-672.

Pool KD, Devous MD, Freeman FJ, Watson BC and Finitas T (1991) Regional cerebral blood flow in developmental stutterers. Archives of Neurology, 48, 509-512.

Quaker SE (1977) Dysarthria: an unusual side effect of tricyclic anti-depressants. British Medical Journal, 2, 97.

Robinson RG and Starkstein SE (1990) Current research in affective disorders following stroke. Journal of Neuropsychiatry and Clinical Neurosciences, 2, 1-14.

Rosenbek J, McNeil MR, Lemme ML, Prescott TE and Alfred AC (1975) Speech and language findings in a chronic dialysis patient; a case report. Journal of Speech and Hearing Disorders, 40, 245-252.

Rosenbek J, Messert B, Collins M and Wertz R (1978) Stuttering following brain damage. Brain and Language, 6, 82-86.

Schatzberg AF, Cole JO and Blumer DP (1978) Speech blockage: a tricyclic side effect. American Journal of Psychiatry, 135, 600-601.

Soroker N, Bar-Israel Y, Schecter I and Solzi P (1990) Stuttering as a manifestation of right-hemisphere subcortical stroke. European Neurology, 30, 268-270.

Stump DA and Williams R (1980) The non-invasive measurement of regional cerebral circulation. Brain and Language, 9, 35-46.

Wingate ME (1964) A standard definition of stuttering. Journal of Speech and Hearing Disorders, 29, 484-489.

Wood F, Stump DA, McKeehan A, Sheldon S and Proctor J (1980) Patterns of cerebral flow during attempted reading aloud by stutterers both on and off haloperidol medication; evidence for inadequate left activity during stuttering. Brain and Language, 19, 141-144.

(Received 8 August 1994; accepted as revised 20 October 1994) 


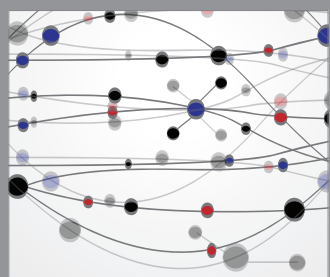

The Scientific World Journal
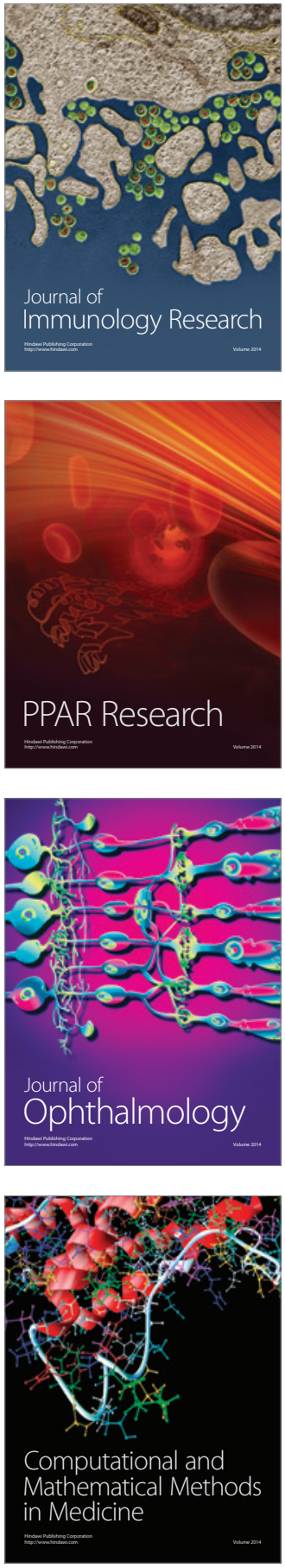

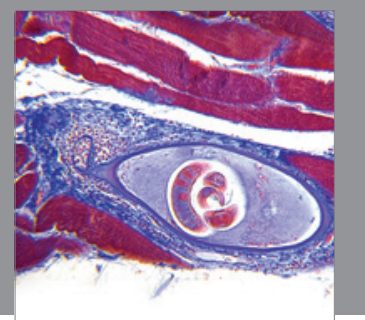

Gastroenterology

Research and Practice
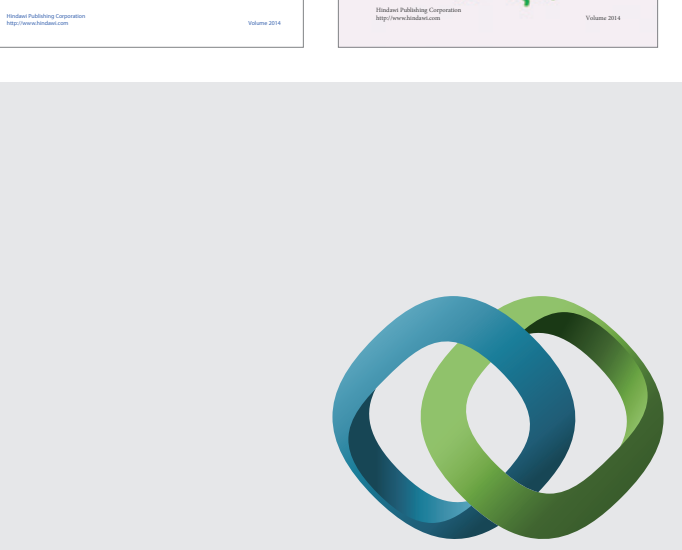

\section{Hindawi}

Submit your manuscripts at

http://www.hindawi.com
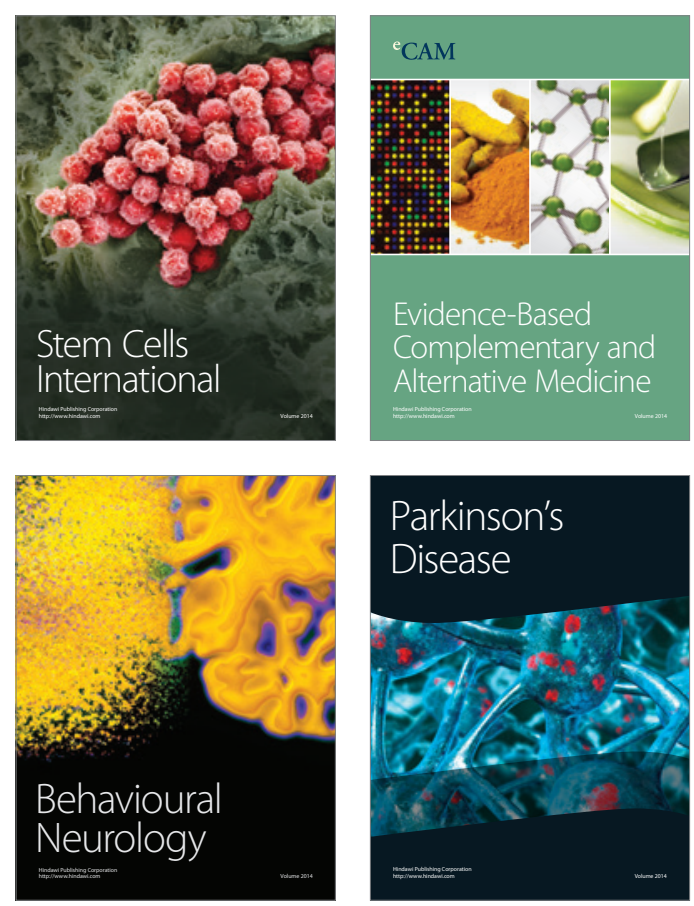

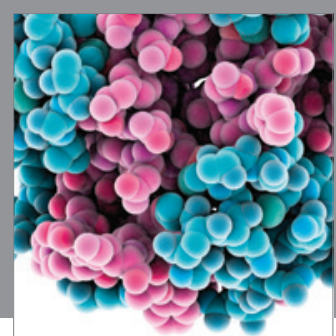

Journal of
Diabetes Research

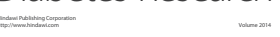

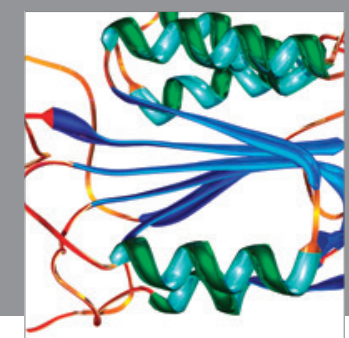

Disease Markers
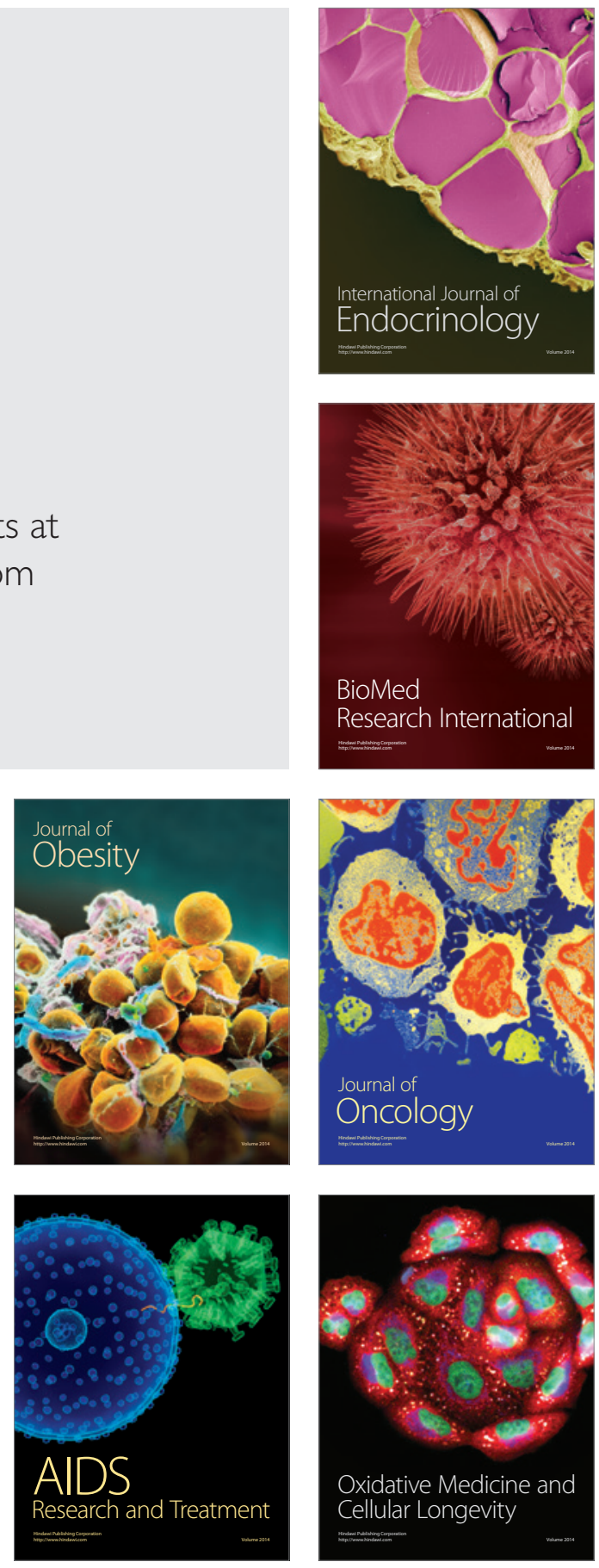